\title{
Endoscopic and Histological Evaluation of Chronic Gastritis in Yemen
}

\author{
Murad A. Mukbel, Al-Haimi M. Ahmed \\ Department of Internal Medicine, Faculty of Medicine and Health Science, Sana'a University, Yemen
}

\begin{abstract}
Aim: To study the prevalence of $\mathrm{H}$. pylori infection; identify the endoscopic findings associated with $\mathrm{H}$. pylori infection and to determine relation between endoscopic and histological findings of chronic gastritis in the presence of $\mathrm{H}$. pylori. Patients and Methods: One hundred fifty six consecutive patients with dyspepsia referred for upper gastrointestinal endoscopy were enrolled in this study. Assessment of $\mathrm{H}$. pylori was based on the urease test and histological examination of gastric biopsy specimens. Results: One hundred and fifty-six consecutive patients (127 males, 29 females) with a mean age of 38.6 years (range 18 to 67years) were studied. $\mathrm{H}$. pylori were positive in 125 patients (80.1\%) and negative in 31 patients (19.9\%). Gastritis was found in 96 patients (61.5\%) of all patients. H. pylori were found in $93.8 \%$ (90/96) of patients with gastritis and $58.3 \%$ (35/60) of patients without gastritis. Association between $\mathrm{H}$. pylori infection and gastritis was statistically significant $(P<0.001)$. The following endoscopic findings were identified in the patient infected with $\mathrm{H}$. pylori:erythema, edema, exudate, raised erosion, antral nodularity and rugal atrophy. The specificity of macroscopic diagnosis in comparison to histological diagnosis of erosive gastritis, atrophic gastritis, nodular gastritis and erythematous/exudative gastritis were high $100 \%$, $98 \%, 93 \%$ and $79 \%$ respectively. Conclusions: i) Prevalence of $\mathrm{H}$. pylori infection is high and is strongly associated with the development of chronic gastritis. ii) Endoscopic findings are reliable indicator of $\mathrm{H}$. pylori associated gastritis.
\end{abstract}

Keywords: Helicobacter Pylori, chronic gastritis, endoscopy, Histological gastritis

\section{Introduction}

Helicobacter pylori (H. pylori) remain the most common chronic infection that is responsible for the pathogenesis of chronic gastritis, duodenal ulceration and probably gastric carcinoma ${ }^{(1-4)}$. The prevalence of $\mathrm{H}$. pylori infection correlates with socioeconomic conditions thus it is more prevalent in developing countries than in developed ones ${ }^{(5-7)}$. In developing countries, $70-90 \%$ of the population is positive for H.pylori. Assessment of $\mathrm{H}$. pylori status is the most effective approach for reducing the risk of $\mathrm{H}$. pylori associated complications. The prevalence of $\mathrm{H}$. pylori infection in Yemen and nearby country was high in reported literature ${ }^{(7,8)}$. H. pylori colonization of gastric mucosa is associated with epithelial damage in response to immune reaction within the stomach, which can be identified histologically as gastritis. Therefore, biopsy specimens of the mucosa for the presence or absence of $\mathrm{H}$. pylori should be obtained during or after visual evaluation of gastric mucosa. The association between endoscopic features of $\mathrm{H}$. pylori and histological findings has been reported in the literature yet, still a matter of debate. Because of discrepancies between macroscopic appearance and histological finding of gastritis, H. pylori-related gastritis cannot be diagnosed via endoscopy alone. Additionally, 
H. pylori infection has been suggested to have poor association with common endoscopic findings $s^{(9-12)}$. Many studies ${ }^{(12,26)}$ revealed that the presence of macroscopic abnormalities were higher in $\mathrm{H}$. pylori associated gastritis than in non-H. pylori. The updated Sydney system for classification of gastritis has shown an association between histological gastritis and $\mathrm{H}$. pylori infection $^{(13)}$. The aim of this study is to evaluate the correlation between macroscopic finding, histomorph-ological finding of gastritis, and the presence of $\mathrm{H}$. pylori in the gastric mucosa.

\section{Patients and Methods}

This study was undertaken at Typical Police Hospital in Sana'a, capital of Yemen. Consultant endoscopist with 25 years' experience performed endoscopy. From March 2010 until to August 2011, we prospectively evaluated 156 patients referred for upper gastrointestinal endoscopy. Patients were included in the study only if they suffered from mild to moderate symptoms of dyspepsia. The exclusion criteria were history of $\mathrm{H}$. pylori infection; treatment of $\mathrm{H}$. pylori infection with antibiotics; proton pump inhibitor or $\mathrm{H}_{2}$ blockers and treatment with NSAID. Patients with history of gastric ulcers, duodenal ulcers, duodenitis, and cancer of stomach, reflux esophagitis, liver cirrhosis, and organ failure in the past or during the present endoscopy were excluded. The presence of $\mathrm{H}$. pylori infection in the stomach was assessed based on the macroscopic patterns. Endoscopic procedures were performed with Karl Storz endoscope system (Karl Storz 13801 PKS-X endoscope with a Camera Processor Karl Stors Telecom SL 11 202130 20, Processor Karl Storz Xenon 100201325 20 and Sony color video printer UP 21MD). All endoscopy videos and captured pictures were recorded into a computer video recorder. Another endoscopy specialist reviewed these Images independently. An in- formed, written consent was obtained from each patient.

Diagnosis of $\mathrm{H}$. pylori infection

Infection with $\mathrm{H}$. pylori was diagnosed if $\mathrm{H}$. pylori were observed histologically and rapid urease test was positive.

Histological analysis

Biopsy specimens were taken: two from the anterior and posterior antrum, two from the anterior and posterior body, and two from any additional area of abnormality. Specimens for histological analysis were placed in $10 \%$ formalin solution and routinely processed. The hematoxylin, eosin stain, and modified Giemsa stain were used for identification of $\mathrm{H}$. pylori. The histopathological features were reported according to the Sydney classification ${ }^{(13,14)}$ by one histopathologist, who was blinded to the clinical and endoscopic findings but was informed about the gastric region where each biopsy specimen had been obtained. Diagnostic criteria were applied to histological features and each histopathological parameter (chronic inflammation, activity, atrophy, intestinal metaplasia and $\mathrm{H}$. pylori density) were graded for assessment of their severity as $0=$ absent, $1=$ mild, $2=$ moderate or $3=$ in the corpus and antrum (Table 1).

\section{Endoscopic diagnosis}

According to the Sydney classification ${ }^{(15)}$ of endoscopic abnormality, the following endoscopic mucosal features were defined: erythema (punctate and confluent), oedema, exudate (punctate and confluent), friability, flat and raised erosions, rugal hyperplasia, atrophy, visibility of the vascular pattern, intramural bleeding spots, and nodularity (fine and coarse). Combinations of these mucosal changes with subjective assessment of severity as mild, moderate, or severe were used to classify endoscopic gastritis into seven categories (Table 2). 

Table 1: Classification of histological gastritis and diagnostic criteria

\begin{tabular}{|l|l|l|}
\hline Histological parameter & Definition & Grading guidelines \\
\hline Chronic inflammation & $\begin{array}{l}\text { Increase in lymphocytes and } \\
\text { plasma cells in the lamina } \\
\text { propria neutrophil polymorph }\end{array}$ & $\begin{array}{l}\text { Scored as 0: None, 1: mild, 2: moderate or 3: se- } \\
\text { vere }\end{array}$ \\
\hline Activity & $\begin{array}{l}\text { Neutrophil polymorph infiltra- } \\
\text { tion of the lamina propria, pits } \\
\text { or surface epithelium }\end{array}$ & $\begin{array}{l}\text { Scored as 0: None, 1: mild }(<1 / 3 \text { of pits and sur- } \\
\text { face infiltrated), 2: moderate }(1 / 3-2 / 3), \text { or 3: se- } \\
\text { vere }(>2 / 3)\end{array}$ \\
\hline Atrophy & $\begin{array}{l}\text { Loss of specialized glands } \\
\text { from either antrum or corpus }\end{array}$ & $\begin{array}{l}\text { Scored as 0: None, 1: mild, 2: moderate or 3: se- } \\
\text { vere }\end{array}$ \\
\hline Intestinal metaplasia & $\begin{array}{l}\text { Intestinal metaplasia } \\
\text { (all sub-types) of the foveolar } \\
\text { cells or surface epithelium }\end{array}$ & $\begin{array}{l}\text { Scored as 0: None, 1: mild }(<1 / 3 \text { of mucosa in- } \\
\text { volved), 2: moderate }(1 / 3-2 / 3), \text { or } 3: \text { severe }(>2 / 3)\end{array}$ \\
\hline H. pylori & $\begin{array}{l}\text { Density of Helicobacter-like } \\
\text { organisms overlying epitheli- } \\
\text { um }\end{array}$ & $\begin{array}{l}\text { Scored as 0: None, 1: mild }(<\text { Scattered organisms } \\
\text { covering }<1 / 3 \text { of the surface, mild colonization), } \\
\text { 2: moderate }(1 / 3-2 / 3, \text { intermediate numbers, } \\
\text { moderate colonization), or 3: severe (large clus- } \\
\text { ters or a continuous layer }>2 / 3 \text { of the surface })\end{array}$ \\
\hline \multicolumn{2}{|l|}{} \\
\hline
\end{tabular}

Table 2: Endoscopic Classification of macroscopic feature of gastric inflammation

\begin{tabular}{|c|c|}
\hline Diagnosis & Diagnostic criteria \\
\hline $\begin{array}{l}\text { Erythematous/exudative } \\
\text { gastritis }\end{array}$ & $\begin{array}{l}\text { Patchy erythema with mild friability, loss of lustre, occasionally } \\
\text { punctate exudate and finely granular surface }\end{array}$ \\
\hline Raised erosive gastritis & $\begin{array}{l}\text { Solitary, multiple or numerous of discrete lesion of elevated mu- } \\
\text { cosa, capped by central defect often with focal erythema }\end{array}$ \\
\hline Flat erosive gastritis & $\begin{array}{l}\text { Mucosal erosive break varying in size from pin point to approxi- } \\
\text { mately } 1 \mathrm{~cm} \text { in diameter which appear as whitish-greyish patches } \\
\text { surrounded with or without erythematous mucosa and covered } \\
\text { with a layer of exudate }\end{array}$ \\
\hline Atrophic gastritis & $\begin{array}{l}\text { Clearly visible submucosal vascular pattern in a non-distended } \\
\text { stomach }\end{array}$ \\
\hline Nodular gastritis & Fine or coarse nodularity of mucosal surface \\
\hline Hemorrhagic gastritis & $\begin{array}{l}\text { Punctate or ecchymotic reddish or brown-blackish flecks present } \\
\text { in the gastric wall }\end{array}$ \\
\hline Rugae hypertrophy & $\begin{array}{l}\text { Irregularity of mucosa, hyperrugosity or enlarged folds of greater } \\
\text { curvature in corpus }\end{array}$ \\
\hline
\end{tabular}

\section{Statistical Methods}

Statistical analysis was done using SPSS 18 for windows. Odds ratios (OR) for endoscopic gastritis were derived by multiple logistic regression analysis. Sensitivity, specificity, positive and negative predictive values were calculated. Comparison bew-teen $\mathrm{H}$. pylori test results and gastritis was calculated by Chi Square $\left(\chi^{2}\right)$ tests. P-value less than 0.05 was considered significant. Sensitivity was defined as the percentage of patients with histologically diagnosed gastritis with chronic inflammation/atrophy or H.pylori positive in stomach of patients exhibiting an endoscopic findings and the specificity is the percentage of patients without histological gastritis or absence of $\mathrm{H}$. pylori. The PPV is the percent's of endoscopic feature in subject with histological gastritis. NPV is absence of endoscopic findings in patients without histological gastritis. Endoscopic findings were compared with histologically-moderate to severe chronic 
inflammation or presence of $\mathrm{H}$. pylori; endoscopically visible vessels and absence of rugae were compared with histologically-moderate to severe atrophy.

\section{Results}

One-hundred and fifty-six patients complaining of dyspepsia referred for upper gastrointestinal endoscopy were included in the study. Twenty-nine patients were female and 127 male with a mean age of 38.6 years (range 18 to 65 years). Mean age, sex ratio, and $\mathrm{H}$. Pylori status ratio were obtained using T. test and Fisher exact test (Table 3 and Figure 1). Specific endoscopic abnormalities in infected and none infected group are shown in table-4. Endoscopic diagnosis in infected and none infected group are presented in Table 5 and Figures 2-4. Histological diagnosis is presented in Table 6. Sensitivity, specificity, PPV and NPV of endoscopic features in comparison with histologically diagnosed moderate to severe inflammation and moderate to severe atrophy are shown in Table 7

Table 3: Demographic and clinical characteristics of the study patients

\begin{tabular}{|l|llll|}
\hline & $\begin{array}{l}\text { H. pylori } \\
\text { positive }\end{array}$ & $\begin{array}{l}\text { H. pylori } \\
\text { negative }\end{array}$ & Total & P value \\
\hline $\begin{array}{l}\text { No. of patients } \\
\text { Geographical region No. (\%) }\end{array}$ & 125 & 31 & 156 & \\
$\quad 26(74.3 \%)$ & $9(25.7 \%)$ & 35 & $>0.5$ \\
$\quad \begin{array}{l}\text { Sana'a } \\
\quad \text { Others }\end{array}$ & $99(81.8 \%)$ & $22(18.2 \%)$ & 121 & $>0.5$ \\
Gender & 101 & 26 & 127 & \\
$\quad$ Male & 24 & 5 & 29 & $>0.05$ \\
$\quad$ Female & $37.9(18-63)$ & $41.4(21-67)$ & $38.6(18-67)$ & \\
Age (Yrs) Mean (range) & \multicolumn{4}{l}{} \\
\hline
\end{tabular}

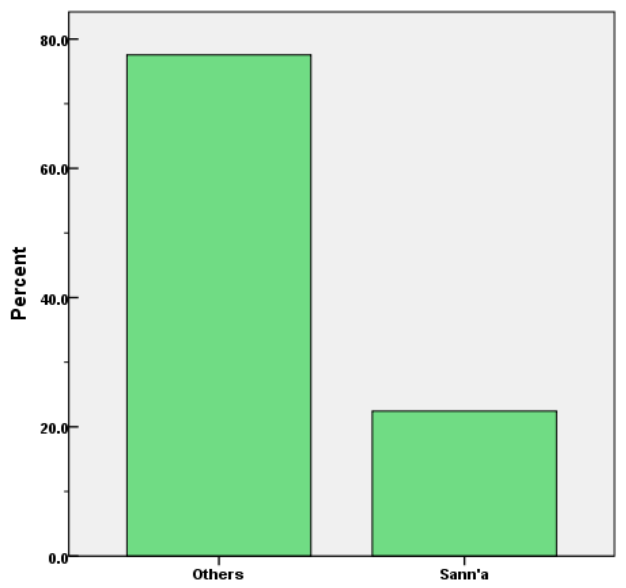

Figure 1: Helicobacter pylori status of study patients

\section{Discussion}

Our aim was to identify the endoscopic findings associated with $\mathrm{H}$. pylori infection and to determine relation between endoscopic and histological findings of chronic gastritis in the presence of $\mathrm{H}$. pylori. Assessment of $\mathrm{H}$. pylori based on the urease test and histological examination of gastric biopsy specimens. $\mathrm{H}$. pylori were positive in 125 patients $(80.1 \%)$ and negative in 31 patients (19.9\%). The prevalence of $\mathrm{H}$. pylori infection in this study was $80.1 \%(125 / 156)$ being somewhat more than the result of recent study performed in Yemen?. The difference may be related to decrease socio-economic status of the family and to different method of $\mathrm{H}$. pylori detection. Gastritis was found in 96 patients $(61.5 \%)$ of all patients and $72 \%$ (90/125) of those was $\mathrm{H}$. pylori positive and $19.4 \%$ (6/31) H. pylori negative. H. pylori was present in $93.8 \%$ (90/96) of gastritis patients, and $58.3 \%(35 / 60)$ of patients without gastritis. Correlation between $\mathrm{H}$. 
pylori infection and gastritis was statistically significant $(P<0.001)$. The rate of $H$. pylori infection in the current study was significantly higher in patients with endoscopic gastritis than that in subjects with normal endoscopic appearance and this is similar to result in previous studies ${ }^{(16,17)}$. Previous studies on the endoscopic features of $\mathrm{H}$. Pylori-related gastritis concluded that $\mathrm{H}$. pylori infection could not be diagnosed by endoscopy alone ${ }^{(9-12)}$. In Yemen, there are no data available on different endoscopic findings associated with gastritis. Our study revealed that $\mathrm{Er}$ ythema (45\%), edema (36\%), exudate (21\%), nodularity (14.4\%), rugal atrophy (11.2\%), raised erosion (10.4\%) and friability (6.4\%) were the most common endoscopic findings in patients infected with $\mathrm{H}$. pylori. Odds ratio was more than one for the following macroscopic finding erythema, edema, exudate, raised erosion, nodularity and friability. The odds ratio for hemorrhage and rugal hypertrophy were less than one and this suggests that hemorrhage and rugal hypertrophy were not associated with $\mathrm{H}$. pylori related gastritis. So, the following endoscopic findings erythema, edema, friability, exudate, raised erosion, rugal atrophy, and nodularity are identified in $\mathrm{H}$. pylori infection.

In our study $95 \%$ confidence interval for the erythema, edema, friability does not contain the value of one and therefore is consistent with an odds ratio that is statistically significant but 95\% confidence interval for raised erosion, nodularity, friability and rugal atrophy included one, which represent statistically not significant.

Table 4: Association of $\mathrm{H}$. pylori and endoscopic features using a logistic regression model

\begin{tabular}{|c|c|c|c|c|c|c|}
\hline \multirow[t]{2}{*}{ Findings } & \multirow{2}{*}{$\begin{array}{l}\text { Infected } \\
(n=125) \\
\text { No (\%) }\end{array}$} & \multirow{2}{*}{$\begin{array}{l}\text { Not infected } \\
(n=31) \\
\text { No }(\%)\end{array}$} & \multirow{2}{*}{$\begin{array}{l}\text { Odds } \\
\text { ratio }\end{array}$} & \multicolumn{2}{|c|}{$95 \% \mathrm{Cl}$} & \multirow[t]{2}{*}{$P$ value } \\
\hline & & & & Lower & Upper & \\
\hline -Erythema & $56(45 \%)$ & $2(6.5 \%)$ & 11.77 & 2.69 & 51.47 & $<0.005$ \\
\hline -Edema & $45(36 \%)$ & $2(6.5 \%)$ & 8.16 & 1.86 & 35.78 & 0.005 \\
\hline -Exudate & $26(21 \%)$ & $1(3.2 \%)$ & 7.88 & 1.03 & 60.51 & $<0.05$ \\
\hline -Nodularity & $18(14.4 \%)$ & $2(3.2 \%)$ & 2.43 & 0.54 & 11.13 & 0.25 \\
\hline -Rugal atrophy & $14(11.2 \%)$ & $2(3.2 \%)$ & 1.83 & 0.39 & 8.51 & 0.44 \\
\hline -Erosion & $13(10.4 \%)$ & $1(3.2 \%)$ & 3.48 & 0.44 & 27.69 & 0.23 \\
\hline -Friability & $8(6.4 \%)$ & $1(3.2 \%)$ & 2.05 & 0.25 & 17.04 & 0.51 \\
\hline -Hemorrhage & $3(2.4 \%)$ & $2(6.5 \%)$ & 0.36 & 0.06 & 2.23 & 0.27 \\
\hline -Rugae hypertrophy & $3(2.4 \%)$ & $1(3.2 \%)$ & 0.74 & 0.07 & 7.34 & 0.80 \\
\hline
\end{tabular}

Ohkusa et $\mathrm{al}^{(18)}$ demonstrated a correlation between $\mathrm{H}$. pylori and edema, erythema and reddish streaks. They stated that even simple careful visual evaluation of the mucosa revealed the diagnoses of erythema and edema, which correlated well with $\mathrm{H}$. pylori infection. The present study revealed similar association be- tween erythema, edema and exudate and H. pylori infection. In 96 of 156 patients the following endoscopic diagnosis were found: erythematous/exudative gastritis (32\%), nodular gastritis (10\%), atrophic gastritis ( $8 \%)$, erosive gastritis ( $8 \%)$, hemorrhagic (2\%) and hypertrophic gastritis (2\%). 
Table 5: Endoscopic diagnosis in patients with and without $\mathrm{H}$. pylori

\begin{tabular}{|c|c|c|}
\hline Finding & $\begin{array}{l}\text { Infected } \\
n=125\end{array}$ & $\begin{array}{l}\text { Not } \\
\text { infected } \\
n=31\end{array}$ \\
\hline $\begin{array}{l}\text {-Erythematous/exudative } \\
\text { gastritis }^{\dagger}\end{array}$ & 48 & 2 \\
\hline -Erosive gastritis $^{\ddagger}$ & 12 & 0 \\
\hline -Atrophic gastritis ${ }^{\dagger}$ & 11 & 1 \\
\hline -Nodular gastritis ${ }^{\dagger+}$ & 15 & 1 \\
\hline -Hemorrhagic gastritis ${ }^{\mathrm{Ht}}$ & 1 & 2 \\
\hline -Rugae hypertrophy ${ }^{\ddagger}$ & 3 & 0 \\
\hline -Normal endoscopy ${ }^{\dagger}$ & 35 & 25 \\
\hline
\end{tabular}

Erythematous/exudative, atrophic and nodular gastritis was statistically significant compared with normal endoscopic appearance. which could be considered as reliable predictor of H. pylori infection. Erythematous/exudative gastritis was the most common endoscopic diagnosis in our study (32\%) with high rate of mucosal colonization by H. pylori ( $96 \%)$. Although the endoscopic features of erythematous/exudative gastritis are infrequently seen, its high prevalence in our study can be explained by severe $\mathrm{H}$. pylori infection mainly of the antrum.

Table 6: Histological findings of gastric biopsy in study sample

\begin{tabular}{|l|llll|}
\hline Finding: & \multicolumn{4}{|c|}{ Severity } \\
& Score 0 & Score 1 & Score 2 & Score 3 \\
& $\mathrm{N}(\%)$ & $\mathrm{N}(\%)$ & $\mathrm{N}(\%)$ & $\mathrm{N}(\%)$ \\
\hline H.pylori $\dagger$ & & $36(23 \%)$ & $48(31 \%)$ & $32(20.5 \%)$ \\
Chronic inflammation & $40(25.5 \%)$ & $67(43 \%)$ & $39(25 \%)$ & $9(5.8 \%)$ \\
Atrophy & $132(84.6 \%)$ & $11(7 \%)$ & $12(7.6 \%)$ & $1(0.6 \%)$ \\
\hline
\end{tabular}

$0=$ none, $1=$ mild, $2=$ moderate or $3=$ severe

The sensitivity, specificity, and PPV of endoscopic diagnosis in comparison to histological diagnosis of erythematous/ exudative gastritis in our study were $79.2 \%, 80.7 \%$, and $81 \%$ respectively. Whilst Tytgat ${ }^{(19)}$ have suggested that the more severe the endoscopic abnormalities, the better is the correlation with histology, others ${ }^{(20)}$ have suggested that when erythema is the most conspicuous endoscopic abnormalities, histologic chronic gastritis has been found in $75 \%$ or more of such patients. We agree with this conclusion because erythematous/exudative gastritis in current study had a good sensitivity and specificity for the diagnosis of $\mathrm{H}$. pylori infection. So endoscopic features of Patchy erythema with mild friability, loss of luster, occasionally punctate exudates and finely granular surface which commonly labeled as gastritis would be acceptable for use as screening test in diagnosis of severe $\mathrm{H}$. pylori infection.

Table 7: Sensitivity, and Specificity of endoscopic features for histologically-diagnosed moderate to severe inflammation of gastric mucosa

\begin{tabular}{|l|llll|}
\hline Finding n (\%) & Sensitivity & Specificity & PPV & NPV \\
\hline Erythematous/exudative gastritis & $79 \%$ & $81 \%$ & $76 \%$ & $81 \%$ \\
Erosive gastritis & $25 \%$ & $100 \%$ & $100 \%$ & $40 \%$ \\
Atrophic gastritis & $69 \%$ & $98 \%$ & $75 \%$ & $97 \%$ \\
Nodular gastritis & $29 \%$ & $93 \%$ & $88 \%$ & $43 \%$ \\
Hemorrhagic gastritis & $2 \%$ & $87 \%$ & $33 \%$ & $22 \%$ \\
Rugae hypertrophy & $4 \%$ & $93 \%$ & $67 \%$ & $23 \%$ \\
\hline
\end{tabular}




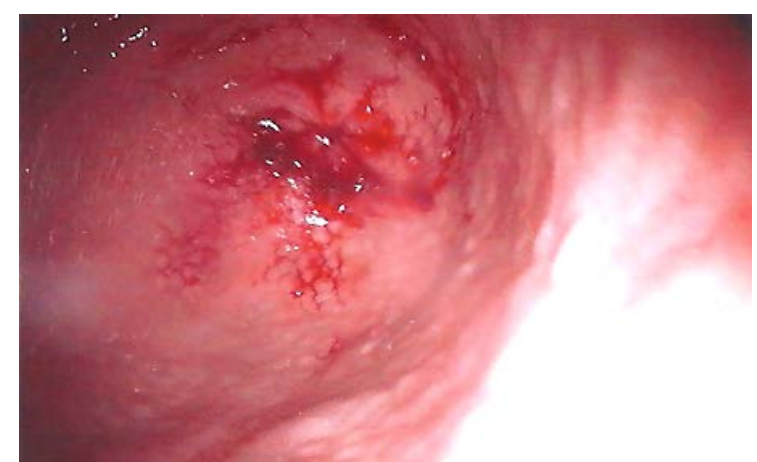

Figure 2: Panoramic view of the antrum

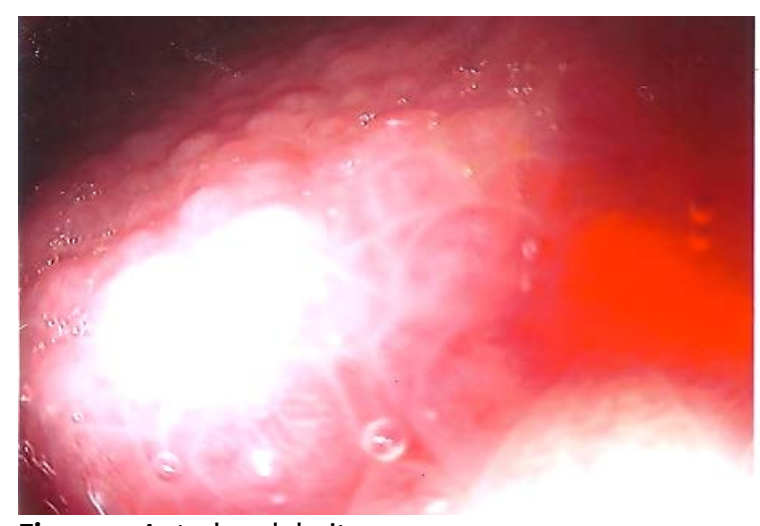

Figure 3: Antral nodularity

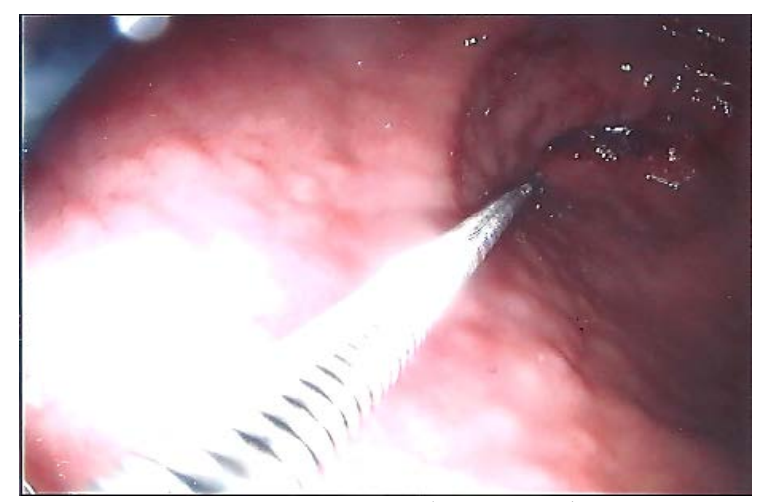

Figure 4: Antrum-anterior wall (nodularity)

Antral nodularity has been reported in pediatric patients ${ }^{(21)}$ with $\mathrm{H}$. pylori. Antral nodularity recently has been proposed to show a potential endoscopic feature of $\mathrm{H}$. pylori infection in adults ${ }^{(22)}$. The specificity of antral nodularity for $\mathrm{H}$. pylori gastritis has previously been reported ${ }^{(22-25)}$. Laine $\mathrm{L}$ and colleagues ${ }^{25)}$, observed that, finding of body area gastricae and nodularity are insensitive as predictors of $\mathrm{H}$. pylori and histologic gastritis but antral nodularity had a high specificity for $\mathrm{H}$. pylori (specificity of $96 \%$ and sensitivity of $32 \%$ ) and gastritis (93\%), with positive predictive values of $90 \%$ and $75 \%$, respectively. He also revealed that, a combination of antral nodularity and prominent body area gastricae, although seen in only $10 \%$ of the subjects, had a specificity and positive predictive value of $100 \%$ for $\mathrm{H}$. pylori. The finding in our study for specificity, sensitivity, and PPV were 29\%, 93\% and $88 \%$ respectively, which is similar to the results of mentioned study. Bah et al ${ }^{(9)}$ investigated the macroscopic feature of $101 \mathrm{pa}-$ tients referred for upper GIT endoscopy. They observed that, the antral gastritis or erosion showed the Sensitivity of $75 \%$ and specificity of $63 \%$ to histological examination. They stressed that, it is not possible to diagnosed $\mathrm{H}$. pylori-related gastritis on the base of endoscopic features. Another study by Calabrese et $\mathrm{al}^{(10)}$ found a normal endoscopic picture in $15.1 \%$, erythematous/exudative gastritis in $42.9 \%$, chronic erosive change in $13.7 \%$, atrophic change in $8.2 \%$ and nodular change in $20.1 \%$. Correlation between endoscopic features and histology of antral biopsies was poor with sensitivity of $91.4 \%$ and specificity of $32.7 \%$. Stolte et al $^{(26)}$ demonstrate that raised erosion of the antrum represent a sequelae of $\mathrm{H}$. pylori-induced gastritis. Khakoo et $\mathrm{al}^{(27)}$ observed that "endoscopic 'raised erosive gastritis' had a $100 \%$ association with histological abnormality. However it did not have an association with any specific histological type of gastritis". Raised erosion in our study is very specific (100\%) but not sensitive for $\mathrm{H}$. pylori gastritis, so it's obvious that our findings are consistent with some authors ${ }^{(26,27)}$ and inconsistent with others ${ }^{(9,10)}$.

We observed that atrophy had high specificity (98\%), sensitivity of $69 \%$ and PPV of $75 \%$. Some studies show that, in the presence of erosion, or frank endo- 
scopic atrophic change, there are usually corresponding histological changes ${ }^{(21,22)}$.

Despite high sensitivity and very low sensitivity of hemorrhage and rugae hypertrophy the number of cases of hemorrhage and rugae hypertrophy is not enough to come out with statistically significant inference. Correlation between $\mathrm{H}$. pylori infection and gastritis was statistically significant $(p<0.001)$. The following endoscopic finding, Erythema, edema, friability, exudate, raised erosion, antral nodularity and rugal atrophy had odds ratio of more than one. Endoscopic features of Patchy erythema with mild friability, loss of luster, occasionally punctate exudates and finely granular surface which commonly labeled as gastritis would be acceptable for use as screening test for diagnosis of severe $\mathrm{H}$. pylori infection. We observe that raised erosion, antral nodularity, rugal atrophy, and erythema are reliable indicator for detecting $\mathrm{H}$. pylori infection.

\section{Conclusions}

We conclude that $\mathrm{H}$. pylori infection is common in Yemen and is strongly associated with the development of chronic gastritis. The most reliable endoscopic indicators for $\mathrm{H}$. pylori infection are erosion, rugal atrophy, antral nodularity and erythema.

\section{References}

1. Graham DY. Pathogenic mechanisms leading to Helicobacter pylori-induced inflammation. Eur J Gastroenterol Hepatol 1992; 4: 9-16.

2. Fox JG, Correa P, Taylor NS, et al. Campylobacter pylori associated gastritis and immune response in a population at increased risk of gastric carcinoma. Am J Gastroenterol 1989; 84(7): 775-781.

3. Uemura N, Okamoto S, Yamamoto S, et al. Helicobacter pylori infection and the de- velopment of gastric cancer. $\mathrm{N}$ Engl J Med 2001; 345(11): 784-789.

4. Anderson LA, Murphy SJ, Johnston BT, et al. Relationship between Helicobacter pylori infection and gastric atrophy and the stages of the oesophageal inflammation, metaplasia, adenocarcinoma sequence: result from the FINBAR case-control study. GUT. 2008; 57(6):734-739.

5. Pettross CW, Appleman MD, Cohen $\mathrm{H}$, Valenzuela JE, Chandrasoma P, Laine LA. Prevalence of campylobacter pylori and association with antral mucosal histology in subjects with and without upper gastrointestinal symptoms. Dig Dis Sci 1998; 33(6):649-653.

6. Everhart JE. Recent developments in the epidemiology of Helicobacter pylori. Gastroenterol Clin North Am 2000; 29(3):559578.

7. Al-Shami HZ, Al-Joufy AY, Al-Haimi M, AlThubhani A, Rajaa M. Prevalence of H. pylori infection Among Patients Underwent Upper Gastrointestinal Tract Endoscopy in Sana'a major Hospitals. Sana'a Univ J Med Sci 2004; 1:16-25

8. Ayoola AE, Ageely HM, Gadour MO, Pathak VP. Prevalence of Helicobacter pylori infection among patients with dyspepsia in South-Western Saudi Arabia. Saudi Med J 2004; 25(10):1433-1438.

9. Bah A, Saraga E, Armstrong D, et al. Endoscopic features of Helicobacter pylorirelated gastritis. Endoscopy 1995; 27(8): 593-596.

10. Calabrese C, Di Febo G, Brandi G, et al. Correlation between endoscopic features of gastric antrum, histology and Helicobacter pylori infection in adults. Ital J Gastroenterol Hepatol 1999; 31(5): 359-365.

11. Redéen $S$, Petersson F, Jönsson KA, Borch $\mathrm{K}$. Relationship of gastroscopic features to histological findings in gastritis and Helicobacter pylori infection in a general population sample. Endoscopy 2003; 35(11): 946-950.

12. Mihara M, Haruma K, Kamada T, et al. The role of endoscopic findings for the diagnosis of Helicobacter pylori infection: evaluation in a country with high prevalence of 
atrophic gastritis. Helicobacter 1999; 4(1):40-48.

13. Dixon MF, Genta RM, Yardley JH, Correa P. Classification and grading of gastritis. The updated Sydney System. International Workshop on the Histopathology of Gastritis, Houston 1994. Am J Surg Pathol 1996; 20(10): 1161-1181.

14. Price AB. The Sydney system: histological division. J Gastroenterol Hepatol 1991; 6(3): 209-222.

15. Tytgat GN. The Sydney system: endoscopic division, endoscopic appearances in gastritis/duodenitis. J Gastroenterol Hepatol 1991; 6(3): 223-234.

16. Sauerbruch T, Schreiber MA, Schüssler $P$, Permanetter W. Endoscopy in the diagnosis of gastritis. Diagnostic value of endoscopic criteria in relation to histological diagnosis. Endoscopy 1984; 16(3):101-104.

17. Fung WP, Papadimitriou JM, Matz LR. Endoscopic, histological and ultrastructural correlations in chronic gastritis. Am J Gastroenterol 1979; 71(3):269-279.

18. Ohkusa et, Fujiki K, Takashimizu I, Kumagai J, Tanizawa T, Eishi Y: Endoscopic and histological comparison of nonulcer dyspepsia with and without Helicobacter pylori infection evaluated by the modified Sydney system. Am J Gastroenterol 2000, 95(9): 21952199.

19. Tytgat GN. Endoscopic gastritis and duodenitis. Endoscopy 1992; 24(1-2): 34-40.
20.Taor RE, Fox B, Ware J, Johnson AG. Gastritis gastroscopic and microscopic. Endoscopy 1975; 7: 209-215.

21. Hassall E, Dimmick JE. Unique features of Helicobacter pylori disease in children. Dig Dis Sci 1991; 36(4):417-423.

22. Grellier L, Tanner P, Grainger SL. Antral nodularity: Macroscopic marker for Helicobacter pylori gastritis. Gut 1993; 34(suppl):S35.

23. Loffeld RJ. Diagnostic value of endoscopic signs of gastritis: with special emphasis to nodular antritis. Neth J Med 1999; 54(3): 96-100.

24. Crocker JD, Bender GN. Antral nodularity, fold thickness, and narrowing. Signs on the upper gastrointestinal series that may indicate chronic active gastritis secondary to Helicobacter pylori. Invest Radiol 1995; 30(8): 480-483.

25. Laine L, Cohen H, Sloane R, MarinSorensen M, Weinstein WM. Interobserver agreement and predictive value of endoscopic findings for $\mathrm{H}$. pylori and gastritis in normal volunteers. Gastrointest Endosc 1995; 42(5):420-423.

26.Stolte M, Bätz C, Eidt S. Giant fold gastritis--a special form of Helicobacter pylori associated gastritis. Z Gastroenterol 1993; 31(5):289-293.

27. Khakoo SI, Lobo AJ, Shepherd NA, Wilkinson SP. Histological assessment of the Sydney classification of endoscopic gastritis. Gut 1994; 35(9):1172-1175. 